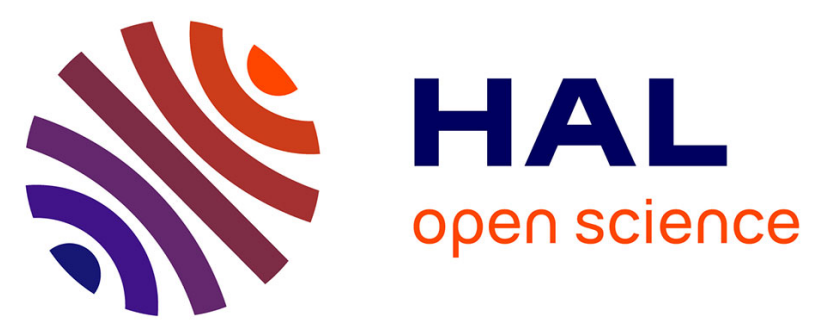

\title{
Ultrathin section preparation of phyllosilicates by Focused Ion Beam milling for quantitative analysis by TEM-EDX
}

Teddy Parra, Olivier Beyssac, Christian Chopin, Florent Moreau, Franck

Bourdelle

\section{To cite this version:}

Teddy Parra, Olivier Beyssac, Christian Chopin, Florent Moreau, Franck Bourdelle. Ultrathin section preparation of phyllosilicates by Focused Ion Beam milling for quantitative analysis by TEM-EDX. Applied Clay Science, 2012, 59-60, pp.121-130. 10.1016/j.clay.2012.02.010 hal-02270195

\section{HAL Id: hal-02270195 \\ https://hal.sorbonne-universite.fr/hal-02270195}

Submitted on 23 Aug 2019

HAL is a multi-disciplinary open access archive for the deposit and dissemination of scientific research documents, whether they are published or not. The documents may come from teaching and research institutions in France or abroad, or from public or private research centers.
L'archive ouverte pluridisciplinaire HAL, est destinée au dépôt et à la diffusion de documents scientifiques de niveau recherche, publiés ou non, émanant des établissements d'enseignement et de recherche français ou étrangers, des laboratoires publics ou privés. 


\title{
Ultrathin section preparation of phyllosilicates by Focused Ion Beam milling for quantitative analysis by TEM-EDX.
}

Franck Bourdelle ${ }^{\mathrm{a}, \mathrm{d}, *}$, Teddy Parra $^{\mathrm{b}, *}$, Olivier Beyssac $^{\mathrm{c}}$, Christian Chopin $^{\mathrm{d}}$, Florent Moreau $^{\mathrm{e}}$

- a Department of Geosciences and Environment, University of Cergy-Pontoise, 5 mail Gay Lussac, Neuville-sur-Oise, 95031 Cergy-Pontoise cedex, France

$-{ }^{\mathrm{b}}$ IFP Energies Nouvelles, 1\&4 avenue de Bois Préau, 92852 Rueil-Malmaison cedex, France

- ${ }^{\mathrm{c}}$ IMPMC, UPMC-CNRS, Case courrier 115, 4 Place Jussieu, 75252 Paris cedex 05, France

$-{ }^{\mathrm{d}}$ Ecole normale supérieure - CNRS, Laboratoire de Géologie, 24 rue Lhomond, 75231 Paris cedex 05, France

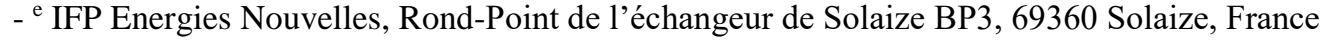

Corresponding author:

Dr Franck Bourdelle

Department of Geosciences and Environment, University of Cergy-Pontoise, 5 mail Gay Lussac, Neuville-sur-Oise, 95031 Cergy-Pontoise cedex, France

E-mail address: franck.bourdelle@u-cergy.fr / Phone number: +33 (0)1 34257353

\begin{abstract}
The composition of the phyllosilicates mica and chlorite is commonly used in thermobarometry to decipher the geological history of rocks. The thermobarometers that have been proposed during the last thirty years rely on the use of electron microprobe (EMP) analyses, with a spatial resolution limited to the micrometer scale. Such a resolution may not be appropriate for the size of clay particles or chemical zoning in very low grade rocks. In this respect, the transmission electron microscope coupled to an X-ray Energy Dispersive spectrometer (TEM-EDX) provides the proper spatial resolution in analysis. It is combined here with Focused Ion Beam (FIB) milling which makes possible in situ preparation of TEM samples with high spatial control and preservation of mineral microtextures. We test the suitability of FIB-milling for TEM-analysis of clay minerals, considering the effects of intrinsic preparation artefacts like amorphization, beam damage, Ga ions implantation and material redeposition. In addition, we evaluate a TEM-EDX analytical protocol adapted to clay minerals and yielding the FIB-section thickness at each analysis point in a non destructive way. The TEM k factors were calibrated on clay powders. A comparison between TEM-EDX and EMP analyses obtained on the same phyllosilicates in FIB and polished sections, respectively, shows excellent agreement, thereby validating the analytical protocol and the use of FIB-sections for the study of clay minerals. The combination of these preparation and analytical procedures opens new avenues for the petrologic study of clay-mineral-bearing assemblages at an unprecedented spatial resolution.
\end{abstract}

Key-words: Focused Ion Beam (FIB), sample preparation, phyllosilicate, analytical TEM, analytical protocol.

\section{Introduction}

Chlorite and mica are two clay minerals, the composition of which is commonly used in chemical thermobarometry (e.g. Battaglia, 2004; Cathelineau, 1988; Cathelineau and Nieva, 1985; Dubacq et al., 2010; Hillier and Velde, 1991; Jahren and Aagaard, 1992; Vidal and Parra, 2000). These geothermobarometers classically rely on chemical data obtained by Electron Microprobe (EMP) Analysis, based on Wavelength Dispersive X-ray Spectroscopy (WDX) or on Energy Dispersive X-ray Spectroscopy (EDX). In both cases, quantitative measurements need to be calibrated with standards of known chemistry to be accurate and reliable; on the other hand, this technique allows for in situ analysis, thus preserving the microtexture and the contacts between mineral phases when using petrographic thin sections. Both the spatial and analytical precision have made EMP the most popular technique for the quantitative analysis of minerals, in particular clay minerals.

However, in low-temperature $\left(\mathrm{T}<300^{\circ} \mathrm{C}\right)$, lowpressure metamorphic rocks $(\mathrm{P}<3 \mathrm{kbar}$ ), the submicrometer size of mineral grains leads in most cases to 'contaminated', i.e. mixed analyses. In such rocks, the use of thermobarometers, all based on local chemical equilibrium (e.g. Vidal and Parra, 2000) between mineral phases, therefore requires higher spatial resolution. Transmission Electron Microscopy (TEM) complemented with an EDX detector offers such a resolution, but requires ultrathin sections transparent to electrons if one wants to preserve the textural relationships between minerals down to the nanoscale. Conventionally, thin sections of mineralogical samples for TEM studies have long been prepared using ion-milling. However, a major disadvantage of this method is the poor precision when positioning the slice plane and therefore the loose control on the location of the section with respect to the mineral microtexture. The focused ion beam milling (FIB) appears as an alternative technique (Wirth, 2004), because it allows for targeting the area that needs to be extracted with a very high-precision (like a SEM) and for cutting heterogeneous samples (e.g. Benzerara et al., 2005; Heaney et al., 2001; Obst et al., 2005). Unfortunately, the FIB technique may involve many artefacts such as structural or chemical damages due to the heavy Ga ions used for the milling. Additionally, a FIB-section is often 
thicker than the ones prepared by the conventional ionmilling method and this may induce thickness effects during the quantitative chemical analysis.

In the present study, the suitability of FIB-milling to prepare ultrathin sections of phyllosilicates for analytical TEM investigations is evaluated. In that respect, a particular attention has been paid to identify and quantify the artefacts due to the FIB-milling process. Then, the protocol for TEM-EDX quantitative analysis of such sections is described with a particular emphasis on the corrections required by the FIB sample thickness. As EMP analysis is the reference tool for thermobarometry, we finally validate the use of FIB-milling and the TEM-EDX analytical protocol by comparison against EMP analyses on the same crystals of phyllosilicates.

\section{Materials and methods}

\subsection{Samples and chemistry calculation}

Two sets of samples were selected to cover a large range of P-T conditions and of types/grain sizes of phyllosilicates. The first set is coming from the Glarus Alps in the central Alps (Switzerland) which is a reference zone for low-grade metamorphism. These samples (noted GL07) are described in Lahfid et al. (2010) and contain small-size particles of illites and chlorites. The second set of sample is from the Tinos Island (Greece, noted TI08), which is a classical example for high-grade metamorphism in the blueschist to eclogite facies (Parra et al., 2002) with coarse-grained chlorite and mica crystals, allowing for a comparison of analyses obtained with both the TEM-EDX and EMP. In each sample two FIBsections were prepared which yields a total of 32 sections (14 samples from Glarus and 2 from Tinos).

In this study, the structural formulae were calculated on the basis of 11 and 14 oxygens for mica and chlorite, respectively, assuming all $\mathrm{Fe}$ as $\mathrm{FeO}$. All $\mathrm{K}, \mathrm{Na}$ and $\mathrm{Ca}$ were assigned to interlayers, and are called "volatile elements" (see below). Element contents are expressed in atoms per formula unit (apfu). The structural formulae were filtered using the criteria detailed by Parra et al. (2002), Vidal and Parra (2000) and Vidal et al. (2001), in order to exclude possible mixed analyses, i.e. those affected by the contribution of an adjacent mineral.

\subsection{Preparation of TEM samples by FIB}

The FIB-milling was performed on conventional polished thin sections after a careful microtextural study with optical microscopy and SEM in order to locate the appropriate mica-chlorite contact zones. The procedure chosen for FIB-milling is similar to the milling procedure described and illustrated in detail in Heaney et al. (2001). In the current study a FEI 200 instrument, belonging to CP2M (University of Aix-Marseille, France) working with a liquid $\mathrm{Ga}$ source at an acceleration voltage of $30 \mathrm{kV}$ was used. The specimens were first sputter-coated with a platinum layer, approximately $15-20 \mathrm{~nm}$ thick. To protect the upper side of the TEM lamella from the milling $\mathrm{Ga}$ - ions an additional, thick layer $(\sim 1 \mu \mathrm{m})$ of organometallic Pt, called "Pt-strap" in Heaney et al. (2001), was deposited ontop of the targeted area prior to the milling. In our study, trenches were first milled on each side of the strap with high current. For the following reduction of thickness of the remaining lamella, the current was reduced stepwise (5000 - 1000 - $300-100-30 \mathrm{pA})$. When milling of the overall shape of the section was finished, the side walls of the lamella were cleaned at a milling current of only $30 \mathrm{pA}$ to preserve the clay matter. Using this milling technique a lamella thickness of approximately 150-200 $\mathrm{nm}$ could be expected at the upper end of the section. The base of the lamella was undercut after tilting the sample. The lamella was then removed from the polished-section and placed on a TEM grid using a micromanipulator under an optical microscope.

\subsection{Modelling of Ga ion beam damages to the thin section}

Beam damages were evaluated using the Monte-Carlo simulation approach (cf. Obst et al., 2005). In such an approach, the trajectories and the collision cascades of Gaions were simulated for a beam incident angle of $1^{\circ}$ from the vertical axis, as occurring during the last step of the milling procedure. The simulation was performed with the "Stopping and Range of Ions in Matter" (SRIM) code version 2008.04 by Ziegler et al. (2010).

\subsection{TEM analyses}

The FIB ultrathin sections were analyzed with a TEMEDX JEOL 2100-F instrument at the materials characterization department of IFP Energies Nouvelles (Solaize, France), using a $200 \mathrm{kV}$ voltage, a counting time of $60 \mathrm{~s}$ and a dead time lower than $15 \%$. The current density was maintained at $1.3 \mathrm{pA} / \mathrm{cm}^{-2}$. The sample tilt angle was $7^{\circ}$, and the total take-off angle is $32^{\circ}$. In these conditions, the spot size is defocused to $50 \mathrm{~nm}$. The experimental EDX standardization consists in the determination of $k$-factors by the analysis of minerals of known chemistry (noted "standards"). The standards chosen are phyllosilicates (Table 1) in order to account for matrix effects, in particular the cation-loss effects that are included in the $k$-factor determination. They are all powders, prepared for the TEM by dropping a clay suspension solution onto a carbon-coated copper grid. Particle thickness is statistically less than $50 \mathrm{~nm}$, allowing one to neglect the fluorescence and absorption effects. Standardization analyses were performed on areas where the layers were visible (i.e. with the beam within or close to the $00 l$ crystalline plane), in order to account for the crystal orientation effects within the $k$-factor determination. For the natural standards, the chemistry was determined by EMP analysis. The synthetic minerals were obtained by the sol-gel method (Hamilton and Henderson, 1968) and crystallized by hydrothermal method.

The TEM-EDX beam trajectory through the lamella was evaluated using a Monte-Carlo simulation approach. This simulation was performed with PENELOPE-2006 software (Salvat et al., 2006). 


\begin{tabular}{llcc}
\hline Standards & Compositions & Calibrated elements & Type \\
\hline Paragonite 1 & $\mathrm{Na} \mathrm{Al}_{2} \mathrm{Al} \mathrm{Si}_{3} \mathrm{O}_{10}(\mathrm{OH})_{2}$ & $\mathrm{Na}, \mathrm{Al}$ & Syn. \\
Paragonite 2 & $\mathrm{Na} \mathrm{Al}_{2} \mathrm{Al} \mathrm{Si}_{3} \mathrm{O}_{10}(\mathrm{OH})_{2}$ & $\mathrm{Na}, \mathrm{Al}$ & Syn. \\
Pyrophyllite & $\mathrm{Al}_{2} \mathrm{Si}_{4} \mathrm{O}_{10}(\mathrm{OH})_{2}$ & $\mathrm{Al}$ & Nat. \\
Talc & $\mathrm{Mg}_{3.05} \mathrm{Si}_{3.95} \mathrm{Al}_{0.02} \mathrm{O}_{10}(\mathrm{OH})_{2}$ & $\mathrm{Mg}$ & Nat. \\
Muscovite & $\mathrm{K}_{0.88} \mathrm{Na}_{0.05} \mathrm{Al}_{2.67} \mathrm{Fe}_{0.2} \mathrm{Mg}_{0.03} \mathrm{Si}_{3.15} \mathrm{O}_{10}(\mathrm{OH})_{2}$ & $\mathrm{Fe}, \mathrm{K}, \mathrm{Al}$ & $\mathrm{Nat}$. \\
Chlorite TT15 & $\mathrm{Fe}_{4.6} \mathrm{Al}_{1.3} \mathrm{Al}_{1.3} \mathrm{Si}_{2.7} \mathrm{O}_{10}(\mathrm{OH})_{8}$ & $\mathrm{Fe}, \mathrm{Al}$ & Syn. \\
Chlorite TT21 & $\mathrm{Fe}_{4.38} \mathrm{Al}_{1.62} \mathrm{Al}_{1.62} \mathrm{Si}_{2.38} \mathrm{O}_{10}(\mathrm{OH})_{8}$ & $\mathrm{Fe}, \mathrm{Al}$ & $\mathrm{Syn}$. \\
Clintonite* & $\mathrm{Ca} \mathrm{Na}_{0.007} \mathrm{Mg}_{2.29} \mathrm{Fe}_{0.05} \mathrm{Fe}^{\mathrm{III}}{ }_{0.11} \mathrm{Al}_{3.39} \mathrm{Si}_{1.20} \mathrm{O}_{10}(\mathrm{OH})_{2}$ & $\mathrm{Mg}, \mathrm{Ca}, \mathrm{Al}$ & $\mathrm{Nat}$. \\
Phengite & $\mathrm{K}_{0.89} \mathrm{Na}_{0.01} \mathrm{Fe}_{0.13} \mathrm{Mg}_{0.42} \mathrm{Al}_{1.90} \mathrm{Si}_{3.55} \mathrm{Ti}_{0.01} \mathrm{O}_{10}(\mathrm{OH})_{2}$ & $\mathrm{Mg}, \mathrm{Fe}, \mathrm{K}, \mathrm{Al}$ & $\mathrm{Nat.}$ \\
\hline
\end{tabular}

Table 1. Minerals used as standards. Syn., synthetic product; Nat., natural product. $* \mathrm{Fe}^{2+} / \mathrm{Fe}^{3+}$ ratio determined by Mössbauer spectroscopy (Joswig et al., 1986). For paragonite, 3000 bars, $580^{\circ} \mathrm{C}$ and 78 days are the synthesis conditions. For chlorites TT15 and TT21, see details for synthesis in Parra et al. (2005).

\subsection{EMP analyses}

The EMP analyses were carried out on a CAMECA SX-100 instrument at the CAMPARIS service in Paris. The analytical conditions were $15 \mathrm{kV}, 10 \mathrm{nA}$, a counting time of $10 \mathrm{~s}$ for the major elements $(\mathrm{Si}, \mathrm{Al}, \mathrm{Mg}, \mathrm{Fe}, \mathrm{Ca})$ and $15 \mathrm{~s}$ for $\mathrm{K}$ and $\mathrm{Na}$. Mineral standards used for calibration were albite $(\mathrm{Na})$, diopside $(\mathrm{Mg}, \mathrm{Si}, \mathrm{Ca})$, orthoclase ( $\mathrm{Al}, \mathrm{K})$, garnet $(\mathrm{Fe})$ and $\mathrm{MnTiO}_{3}(\mathrm{Mn}, \mathrm{Ti})$.

\section{Artefacts and damages by FIB-milling process}

During the first part of the milling procedure, when the energy of the beam current is high, the ion beam severely impacts the fine structure of the matter but the platinum layer set on top of the FIB-section protects it, so that the damages are localized at the periphery of the area of interest (Heaney et al., 2001). However, several contaminations of the FIB-section are possible throughout the following steps of the process, like $\mathrm{Ga}^{2+}$ deposition, amorphization and/or element redeposition (Wirth, 2004). A careful attention was therefore systematically paid to the beam damages caused for low current, low incident angle conditions.

\subsection{Amorphization and $\mathrm{Ga}^{2+}$ beam damages}

During the milling, $\mathrm{Ga}$ atoms are implanted on the surface of the FIB-section, constituting a nonhomogeneous Ga-layer (Giannuzzi et al., 2005). The Ga deposit depends on ion energy, angle of incidence, sample's ion species and targeted material. As a consequence, the incident high-energy Ga-ion beam may alter the structure of minerals by locally inducing an amorphization of the sample surface. The assessment of the damage impact was obtained by Monte-Carlo simulation (Ziegler, 1998; Ziegler et al., 1985). This mathematical approach permits to simulate in three dimensions the penetration of the ions into the matter and the full cascades of energy loss. Figure 1 presents these simulations for $1000 \mathrm{Ga}$-ions accelerated at a voltage of respectively 30, 20 and $10 \mathrm{keV}$ in clinochlore, $\mathrm{Mg}$-sudoite and Mg-celadonite. The impact angle of the ion beam is fixed to $1^{\circ}$, as it is during the thinning of the thin section. The matter density is fixed to $2.7 \mathrm{~g} / \mathrm{cm}^{3}$, which is an average density for the phyllosilicates. The simulation is two-dimensional, the ion beam entering in contact with the matter at the centre of the left side of the figure.

At $30 \mathrm{keV}$, which represents the worst case, the thickness of FIB-section damaged by the ion beam is almost $20 \mathrm{~nm}$ for all the tested minerals. In fact, clinochlore, $\mathrm{Mg}$-sudoite and $\mathrm{Mg}$-celadonite have similar chemistries, and the scale of ion beam damages is approximately the same: the $\mathrm{Ga}^{2+}$ implantation is restricted to the first $10 \mathrm{~nm}$, in both sides of the thin section, and the full cascades of energy loss affects 20-25 $\mathrm{nm}$. Thus, even if a fraction of the ultrathin section may loose its original structure, it can be assumed that the bulk majority of the matter is not influenced by the milling, if the ultrathin section is not too thin. In other words, a thin section with a thickness of $200 \mathrm{~nm}$ is preserved to $80 \%$. Similar results have been obtained by other authors for other materials, as Kim and Dravid (2000) for $\mathrm{Al}_{2} \mathrm{O}_{3}$ and $\mathrm{CaWO}_{4}$. With the FIB used in this study, it is possible to decrease the beam intensity (5000 to $30 \mathrm{pA}$ ) but not the beam current voltage under $30 \mathrm{kV}$ without deteriorating the quality of the working image, which is now possible with the dual-beam FIB systems. Thus, the impact of the beam on the studied clays thin section can be minimized using a lower beam acceleration voltage, with 20 and 15 $\mathrm{nm}$ affected on both side by the full cascade of energy loss for 20 and $10 \mathrm{keV}$ respectively (Figure 1). There is a compromise to be found as the milling time is then longer, but the preserved section thickness is higher compared to the $30 \mathrm{keV}$ case. Even if the numerical simulation represents only an approximation in the case of a crystalline structure, the TEM-observations of a crystalline structure (clay layers) in the ultrathin sections confirm that the majority of the section thickness is not amorphous. An optimization of the milling process (milling time, beam energy and final section thickness) enables to obtain thin section of the area of interest without significant beam damages (amorphization and Ga- 
ions implantation). In fact, the Ga-ions which are implanted on the surface of the FIB-sections constitute a non-homogeneous layer which can be minimized by using a lower-energy beam for the final thinning (Giannuzzi et al., 2005). Moreover, to make sure of the preservation of the crystalline structure in the different minerals, an observation of the layers was systematically carried out with the TEM. In any case, the presence of the Ga-atoms at the ultrathin section surface is not an issue for the TEManalysis as the spectral line of $\mathrm{Ga}$ does not disturb the quantification, since the Ga X-ray energy is significantly lower than $\mathrm{Si}, \mathrm{Mg}, \mathrm{Fe}, \mathrm{Al}$ and $\mathrm{K}$ energies.

\subsection{Redeposition effects}

The redeposition of the pulverized matter (including $\mathrm{Pt}$ from the Pt strap) during the FIB milling is also a problem, because it may form a contamination layer over the surface of the FIB section (Giannuzzi et al., 2005).
The Pt contamination can easily be excluded from the quantification, but the contamination from the sample itself must be considered and, in case of a significant redeposition, the corresponding analyses should be discarded. This artefact is difficult to quantify and there is no straightforward procedure, even if this phenomenon may be minimized by selecting appropriate milling parameters (low-current beam for the milling). In this study, the redeposition is estimated in a qualitative manner by analyzing a crystal near the platinum strap located on top of the ultrathin section where the crystal is supposed to be the less exposed to redeposition. If these analyses contain a high $\mathrm{Pt}$ content (i.e. when the Pt X-ray line is large enough to form a shoulder of the $\mathrm{Si} K \alpha$ line on the EDX spectrum, or when the $\mathrm{PtO}_{2}$ content exceeds $1 \mathrm{wt} \%$ ), this indicates that redeposition (for all elements) was significant, and the corresponding analyses must be rejected.

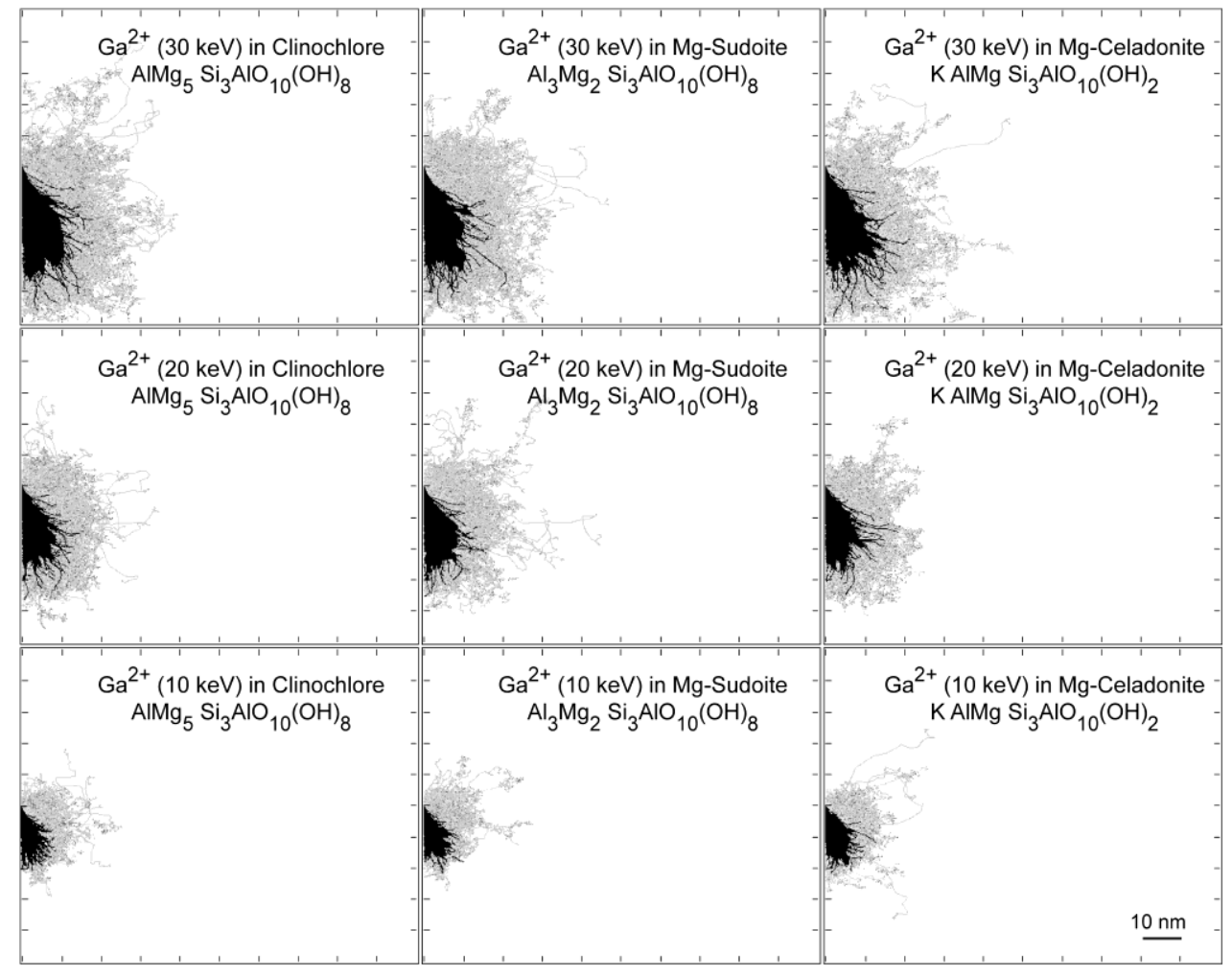

Figure 1. Monte-Carlo simulation of $1000 \mathrm{Ga}$-ion trajectories (black) and the full cascades of energy loss (grey) in clinochlore, Mgsudoite and Mg-celadonite from left to right and for 10, 20 and $30 \mathrm{keV}$ Ga-beam from bottom to top. Simulations were performed with the SRIM 2008.04 code (Ziegler et al., 2010). The Ga-beam hits the sample in the centre of the left side of the FIB section with an incident angle of $1^{\circ}$ on the surface from upside down.

\section{Identification and correction of the analytical artefacts specific to sample preparation}

\section{1. $k$-factors and quantitative corrections}

The EDX analysis uses intensities of X-rays emitted by the matter submitted to an electron beam, which depends on the concentration of each element (Goldstein et al., 1986). The intensity detected (element line intensity, dependent on number and energy of X-rays emitted) by the EDX detector and the chemical quantification are linked by many parameters which are in most cases not known, or not easily estimated. To avoid these difficulties, Cliff and Lorimer (1972) suggested a quantification of each element by comparing its concentration to an element considered as a reference:

$$
\frac{I_{e 1}^{j 1, l 1}}{I_{e 2}^{j 2, l 2}}=\frac{k_{e 1}^{j 1, l 1}}{k_{e 2}^{j 2, l 2}} \frac{c_{e 1}}{c_{e 2}}
$$


with $k_{e}^{j, l}=\frac{1}{A_{e}} \omega_{e}^{j} p_{e}^{j, l}\left(1+T K C_{e}^{j, l}\right) \sigma_{e}^{j}\left(E_{0}\right) \varepsilon\left(E_{e}^{j, l}\right)$

and $\sum_{e=1}^{N} c_{e}=1$

$I_{e 1}$ and $I_{e 2}$ are the measured X-ray intensities on $e 1$ and $e 2$ elements, $c_{e 1}$ and $c_{e 2}$ are the concentrations of the two elements, and $k_{e 1}$ and $k_{e 2}$ are $k$-factors values, determined from thin standards. The $k$-factors equation includes several terms, as the atomic weight $\left(A_{e}\right)$, the fluorescence yield $\left(\omega_{e}\right)$ for $j$, the line's relative weight $\left(p^{j, l}\right)$, the Coster-Kronig transition factor $\left(T K C^{j, l}{ }_{e}\right.$, absent for the $K$ lines), the ionization cross section $\left(\sigma^{j}{ }_{e}\right)$ at the electron's initial energy $\left(E_{0}\right)$, and as the detector efficiency $\left(\varepsilon\left(E^{j, l} e_{e}\right)\right)$. The $k$-factors have to be estimated for each element relative to a reference element which has a $k$-factor set to 1.00. For that purpose, they suggested to use silicon or any other strong X-ray line. The $k$-factors are valid only if the sample thickness is less than $50 \mathrm{~nm}$ (Cliff and Lorimer, 1972, 1975; Jacobs and Baborovska, 1972) so that fluorescence and absorption may be neglible. If the specimen is thick, absorption and fluorescence factors must be estimated in addition to the $k$-factors ratio to obtain a truly quantitative analysis. These absorption and fluorescence factors are included in the equation of the emitted intensity and thus allow correction of the detected intensity (Goldstein et al., 1986). The absorption factor is:

$$
\begin{aligned}
& F\left(\chi_{e}^{j, l}\right)=\frac{\int \Phi_{e}^{j}(\rho z) \exp \left(-\chi_{e}^{j, l} \rho z\right) d(\rho z)}{\int \Phi_{e}^{j}(\rho z) d(\rho z)} \\
& \text { with } \chi_{e}^{j, l}=\frac{\mu_{e}^{j, l}}{\sin \Theta}
\end{aligned}
$$

The fluorescence factor is:

$$
f_{e 1, e 2}^{j 1, l 1, j 2, l 2}=2 \omega_{e 2}^{j 2} c_{e 2} \frac{r_{e 1}-1}{r_{e 1}} \frac{A_{e 1}}{A_{e 2}} \mu_{e 2}^{j 2, l 2}(e 1) \mu_{e 2}^{j 2, l 2}(\text { sample }) \frac{E_{e 1}^{j 1}}{E_{e 2}^{l 2}}(\rho z)^{2}
$$

where $r_{e l}$ is the ratio of absorption coefficient after and before the absorption jump of the $e$ element's $j l$ line, $\Phi_{e}^{j}(\rho z)$ the ionization's density in-depth (Castaing's standardization) and $\Theta$ the X-ray take-off angle. It should be noted that the fluorescence depends on the mass absorption coefficient $\mu^{j, l} e_{e}$ and that both fluorescence and absorption factors depend on the thickness $(z)$ and the density $(\rho)$ of the sample. Figure 2 shows the relative importance of these corrections on quantitative analysis for a non-infinitely thin FIB section of chlorite. We observe that without corrections, the iron content is 2.07 apfu. After fluorescence and absorption corrections, this content is decreased by 0.1 apfu for a minimum thickness of $80 \mathrm{~nm}$. We also note that sample density does not have a strong influence on the correction calculations, and has a negligible effect on the quantification results. As predicted, the correction for thickness modifies notably the chemical results between a FIB section of a negligible thickness $(0-50 \mathrm{~nm})$ and a FIB section with a thickness of $300 \mathrm{~nm}$. In that case, the iron content is decreasing from 2.07 to 1.77 apfu. This example illustrates the necessity, when the FIB section thickness exceeds $50 \mathrm{~nm}$, to evaluate this thickness on the very same area where the analysis is done. This allows one to estimate accurately the effect of fluorescence and absorption.

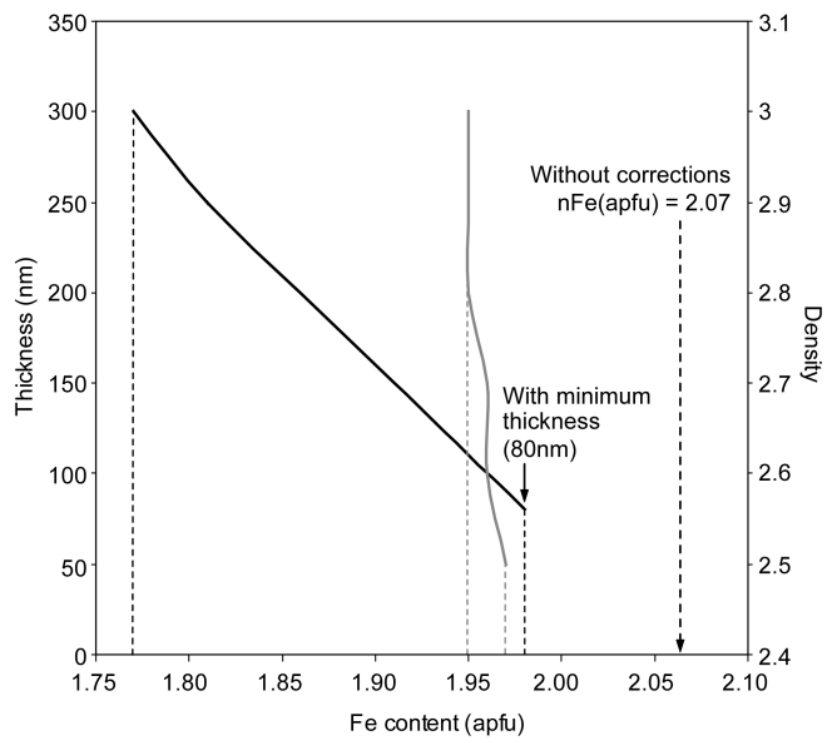

Chemical variation due to the absorption correction for variable ultra-thin section thickness and a fixed density $(d=2.7)$

Chemical variation due to the absorption correction for variable density and a fixed ultra-thin section thickness $(e=100 \mathrm{~nm})$

Figure 2. Influence of fluorescence and absorption corrections according to thickness and density on a chlorite analysis in a FIB section (GL07 26 B1). Density varies from 2.5 to 3. Thickness varies from 80 to $300 \mathrm{~nm}$ as usually observed in our FIB sections.

\subsection{Ultrathin section thickness estimation}

To estimate the thickness of the FIB sections, the simplest method consists in a physical measure between two dots made with the focused beam separated by a known angle. But this method needs a long time analysis, and therefore induces significant radiation damages to the ultrathin section. Moreover, to be precise, this method requires that both sides of the section are parallel which is not the case for FIB sections. Confronted to the same problem, Watanabe and Williams (2006) proposed an alternative method to quantify the chemistry with a modified $\mathrm{k}$-factor (noted $\zeta$ ) that does not depend on the analysis parameters. Altogether, the $\zeta$-factors method (Watanabe et al., 1996; Watanabe and Williams, 1999; 2006) allows one to determine the sample thickness simultaneously with the composition, by an iterative process, together with the absorption and fluorescence corrections. However, the $\zeta$-factors standardization needs accurate estimates of the thickness of the standards used for EDX probe calibration, it requires precise measurement of the beam current density during analysis and does not take into account the specific amorphization of phyllosilicates during analysis. In addition, the application of this protocol to phyllosilicates is very 
limited because the standards used by Watanabe and Williams (2006) are pure-element thin films, whereas phyllosilicates are multi-element oxide compounds with a highly anisotropic structure. Previously, Van Cappellen and Doukhan (1994) proposed an analytic method of plane-parallel specimen which does not require thickness or X-ray take-off angle parameters, and which is based on the principle of electroneutrality of the specimen structure. In the following, we demonstrate the applicability to phyllosilicates of this simple iterative method to estimate the thickness of a FIB-section at each analysis point. The calculation of the thickness is easy and fast with a recent EDX software (JEOL Analysis software in this case) and does not require any additional destructive TEM-beam exposure of the ultrathin sections, as follows.

- First, it is necessary to determine experimentally the real oxygen $k$-factor during the calibration of the EDX probe. Indeed, the pre-unrecorded value, in Figure 3 , is clearly overestimated when applied to phyllosilicates because of the contrasting crystallographic structure between the clays and the TEM manufacturers' standards. The oxygen $k$-factor determination can be made during the EDX standardization step, by the analysis of the standards and estimation of the $k$-factor according to the silicon (Si) reference.

- Second, as the density effects are negligible (in this study), we initially assume a density of 2.7 in accordance with the average density of phyllosilicates.

- The thickness is then calculated from the theoretical oxygen content of phyllosilicates per half unit-cell, based on the fact that (i) the oxygen $k$-factor is rather homogeneous (Figure 3), (ii) oxygen is theoretically the only element whose contents do not vary in phyllosilicate structures, and (iii) it does not intervene directly in the quantification of the other elements.

Since the oxygen content is also a function of thickness, we need an iterative procedure to reach the appropriate thickness that fits the ideal oxygen content. This iterative procedure consists in adjusting each standardized $k$-factor with the valid correction factors by incremental variations of the input thickness. Starting with the normalized composition roughly corrected (based on the ideal structure with $\mathrm{O}=14$ apfu for chlorite and $\mathrm{O}=$ 11 apfu for mica) with a fixed density and an initial thickness of $100 \mathrm{~nm}$, it is possible to deduce a number of cations, which makes possible the quantification of an ideal oxygen atomic $\%$ (i.e. the ratio $[14$ or 11 Oxygens]/[number of cations +14 or 11 Oxygens]). If the result is not equal to the real oxygen atomic\% (calculated from the $\mathrm{O} k$-factor), the thickness is modified, and a new correction is applied on $k$-factors. This calculation is repeated for each analysis until a convergence is reached between ideal and real oxygen atomic $\%$. In this study, this protocol is noted $t$ - $O$-protocol, for estimated thickness from oxygen atomic\% protocol.

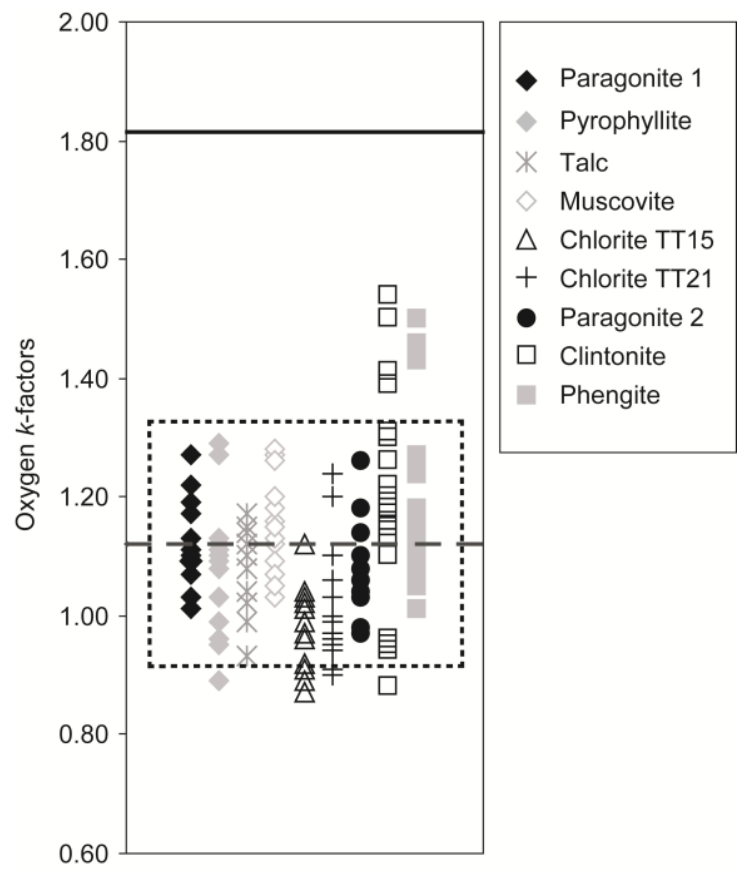

Figure 3. Oxygen $k$-factors deduced from each analysis of the standards $(\mathrm{n}=162)$. The plain line represents the $\mathrm{O} k$-factor given by TEM manufacturers. The dashed line represents the user-determined $k$-factor, which is the average of all deduced $k$ factors. The dashed rectangle represents the standard deviation $(2 \sigma)$ of 0.208 of deduced $k$-factors.

\subsection{Precaution for TEM analysis to minimize polarization effect and contaminations}

In addition to the thickness effects, other artefacts may affect the quantitative results. Bullock et al. (1985) demonstrated that TEM-EDX quantification may be influenced by the crystalline orientation with respect to the incident electron beam. This effect may however be minimized upstream by analyzing the standards used for the EDX calibration and the FIB-sections of clays according to the same crystalline planes. Thus, the gauged $k$-factors take into account the orientation effect. For that purpose, (i) the petrographic thin sections are cut perpendicular to the main cleavage of the rock, i.e. perpendicular to the sheet-silicates $(00 l)$ plane, and (ii) FIB sections are always cut perpendicular to the longest axis of the crystal after careful observation with a SEM. This guarantees that the crystal is cut perpendicular to the $(00 l)$ plane and so minimizes the contribution of the orientation effect to the $k$-factors standardization.

One should also consider that the incident beam may affect an adjacent mineral, inducing contaminations and errors in quantification. Figure 4 presents a Monte-Carlo simulation of the trajectories of beam electrons in the FIB section, with the maximum sample tilt configuration $\left(7^{\circ}\right)$. It shows an increase in the beam spot size of $\sim 50 \%$ at the opposite face of a FIB-section with a thickness of $200 \mathrm{~nm}$. This simulation suggests that analyses of clays must be made at a minimum distance of $30 \mathrm{~nm}$ from the contact with other minerals in order to limit contaminations. Additionally, as the take-off angle is $32^{\circ}$, it is possible that the high-energy X-rays of one mineral could excite the fluorescence of lower-energy lines from adjacent 
minerals. In fact, to completely avoid contamination, fluorescence and absorption effects due to the adjacent minerals must be taking into account in the quantification corrections.

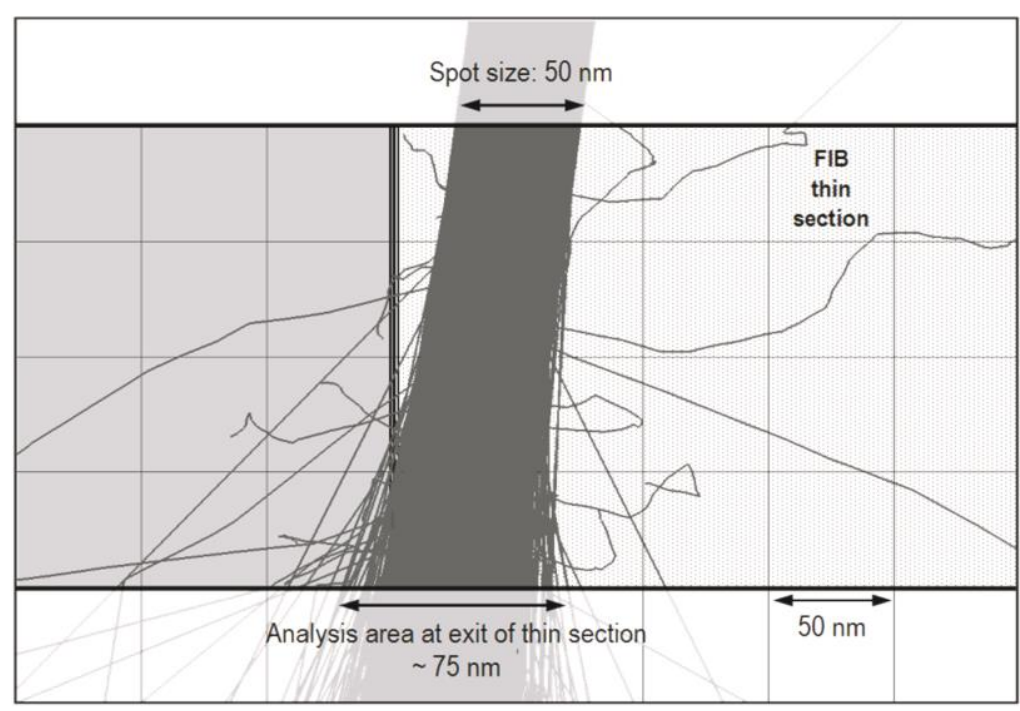

$\square$ Chlorite $\quad \square$ Di-octahedral Mica $\quad$ Chlorite-mica contact

Figure 4. Monte-Carlo simulation of 2000 electron trajectories in a mica with a thickness of $200 \mathrm{~nm}$ and a density of 2.7. Simulation was made with PENELOPE-2006 (Salvat et al., 2006).

\section{Evaluation of the FIB-milling procedure for TEM- EDX quantitative analysis}

\subsection{Evaluation of the t-O-protocol validity}

To check the accuracy of the $t$ - $O$-protocol, we tried to correlate the estimated thickness to an independent analytical criterion such as the number of counts. On Figure 5, we have represented a TEM cartography that shows the number of counts (noted "input rate"), which is actually known to be strongly correlated to the thickness. In theory, we expect the thickness to influence the number of counts detected by the probe, and practically we expect some correlation between the estimated thickness and the input rate. It is necessary to establish that the input rate parameter is independent of the normalized chemistry. This is tested on Figure 6 which shows that the Si and $\mathrm{Al}$ contents of micas show no clear correlation with the input rate. Figure 7 -a shows the estimated thickness versus the input rate (in counts/s) for the mica analyses of all Glarus samples, and that (i) the two parameters are highly correlated and (ii) the great majority of estimated thicknesses fall in the range of expected FIB-section thickness, which is 50-300 nm. The few estimated thicknesses equal to 0 correspond to parts of the FIBsection that are sufficiently thin to belong to the "infinitely thin" case where the corrections do not apply.

However, the calculation procedure to estimate the thickness of FIB sections is very sensitive to the variations of the number of cations. Assumption of all $\mathrm{Fe}$ as $\mathrm{FeO}$ implies a maximum number of cations, and a possible variation of the $\mathrm{Fe}^{3+} / \mathrm{Fe}^{2+}$ ratio will induce significant variations in both the structural formulae and calculated
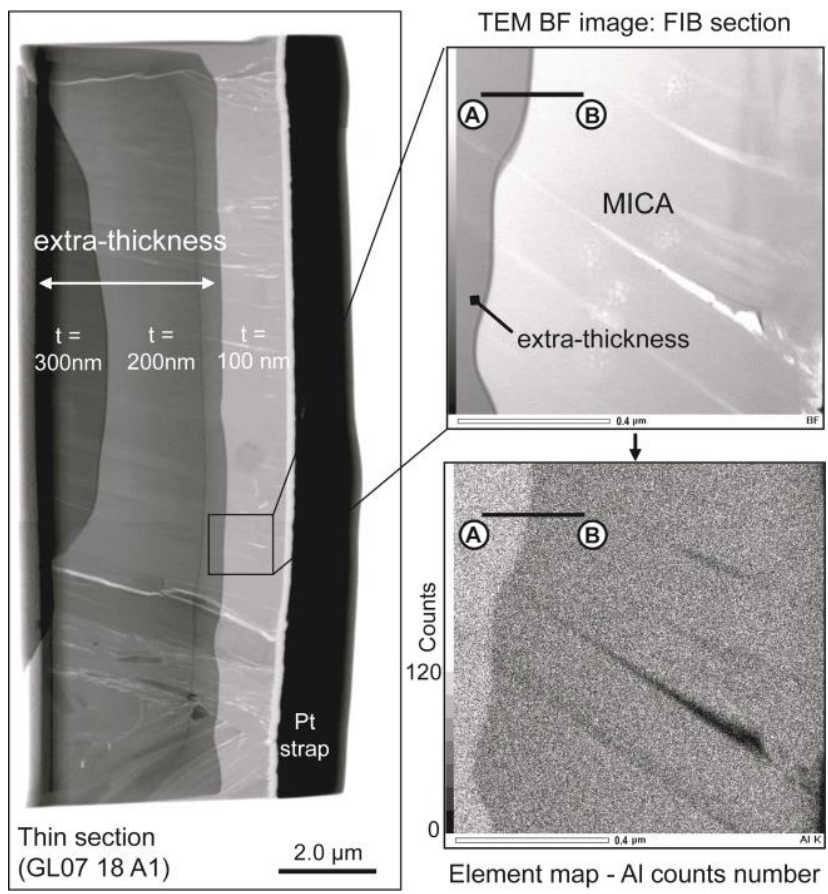

Figure 5. Relation between sample thickness and EDX input rate. The TEM image on the left shows a FIB thin section with three levels of thickness $(\sim 100, \sim 200$ and $\sim 300 \mathrm{~nm})$. The topright image is a close-up view showing the topography of mica in the FIB section, with strong change of thickness along A-B. The bottom-right image is a TEM-EDX cartography representing the number of detected counts in the corresponding area (example of $\mathrm{Al}$ ). thickness. 

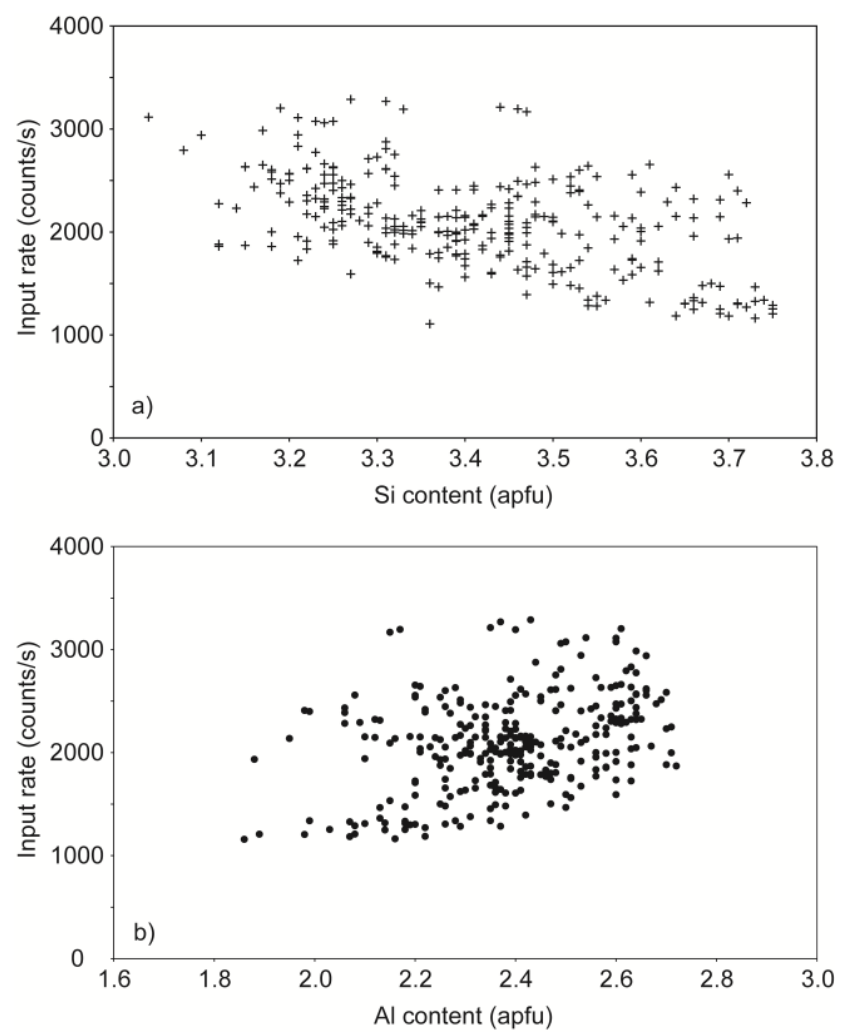

Figure 6. Si (top) and $\mathrm{Al}$ (bottom) contents according to the input rate (in counts/s) for all mica analyses of Glarus samples. $\mathrm{Si}$ and $\mathrm{Al}$ contents are calculated with the fluorescence and absorption corrections, determined from the estimated thicknesses.

For the structural formulae calculation, the absence of quantitative information on the $\mathrm{Fe}^{3+}$ content is an inherent problem to all microanalytical techniques including EMP. For the estimation of thickness, the $\mathrm{Fe}^{3+}$ content is a severe limitation that may completely alter the benefit of the thickness-correction of the analysis. Table 2 shows an example, where, for a mica with an iron content of 0.51 apfu, the estimated thickness may vary by up to $24 \mathrm{~nm}$ (109 nm to $133 \mathrm{~nm}$ ) when assuming either $0 \%$ or $100 \%$ of trivalent iron. In the case of Fe-rich chlorites, the observed correlation is obviously more significant since the number of iron apfu is much higher. As a consequence, the estimation of thickness is only applicable to phyllosilicates with a low atomic\% of iron (e.g. Fe-poor micas), or which have a known $\mathrm{Fe}^{3+} / \mathrm{Fe}^{2+}$ ratio. In this study, we selected the GL07 or TI08 samples because of their low content of iron, in particular for micas, and we based our validation protocol on their analytical results. Since the iron content of chlorites is always too high to obtain an accurate number of cations, we have indirectly calculated their thicknesses from analyses of adjacent $\mathrm{Fe}$ poor micas occurring at less than $100 \mathrm{~nm}$ (noted Mchlorite thicknesses). Figure 7-b represents the M-chlorite thickness against the input rate for each chlorite analysis. As for the micas, a good correlation is observed between input rate and attributed thickness. Importantly, if the
$\mathrm{Fe}^{3+} / \mathrm{Fe}^{2+}$ ratio is known, the thickness of chlorites can directly be estimated from their proper composition. In cases where this ratio is unknown and there are no $\mathrm{Fe}$ poor micas close to the chlorite analysis point, the regression line of Figure 7-b can be used only tentatively to estimate an approximate thickness as a function of the input rate, bearing in mind that such a regression needs to be calibrated for each TEM apparatus.

\subsection{Discussion of corrected TEM results: comparison between EMP and TEM-EDX analysis}

To validate the complete preparation/analysis protocol described in the previous sections, it is necessary to compare the analytical errors attached to the present protocol to those obtained with EMP. To do so, we have performed a circular check on the phyllosilicates from Tinos samples which are large enough to be analyzed by EMPA. Figure 8 presents the comparison of $t$ - $O$-corrected and uncorrected TEM-EDX analyses with the EMP analyses of M-chlorite for $\mathrm{Si}$ and $\mathrm{Fe}$, the most sensitive element to fluorescence and absorption corrections. Figure 9 compares corrected TEM-EDX and EMP analyses of micas for $\mathrm{Mg}$ and $\mathrm{Al}$, which may also be affected by fluorescence and absorption corrections. Two aspects deserve attention: the relative scatters of the datasets, and the agreement of average values. The scattering of the TEM-EDX data is higher than the corresponding ones for EMP analyses. This difference in the results distributions can be explained by the difference in the spatial resolution of the two techniques. The interaction volume from which chemical information is obtained with EMPA has a micrometric size, every analysis giving the average composition of over thousand layers. TEM-EDX provides a distinctly higher spatial resolution in analysis (with a spot size of $50 \mathrm{~nm}$ in our study), imparting to the results a high dependence on compositional heterogeneities and chemical clustering in the sample. Considering these, the low scattering of the Tinos analyses may be due to a relative homogeneity at the micrometric scale (EMP) that is not anymore observed at the nanometric scale (TEMEDX). The use of an average composition calculated on all analyses becomes necessary if one wants to compare the results of the two methods.

For the M-chlorite, in the absence of corrections, iron is over-estimated by the TEM-EDX method which yields Fe content higher than 1.95 apfu, whereas EMP results indicate an average of $1.86 \mathrm{apfu}$. The estimated thickness for this sample varies between 50 and $90 \mathrm{~nm}$, which yields an average correction of - 0.1 apfu for that element and makes the result of chemical quantification nearly identical with both methods. For micas, we also obtained a very good agreement between EMP and corrected TEMEDX average results as shown on Figure 9, with a difference lower than 0.05 apfu when corrections are applied. 

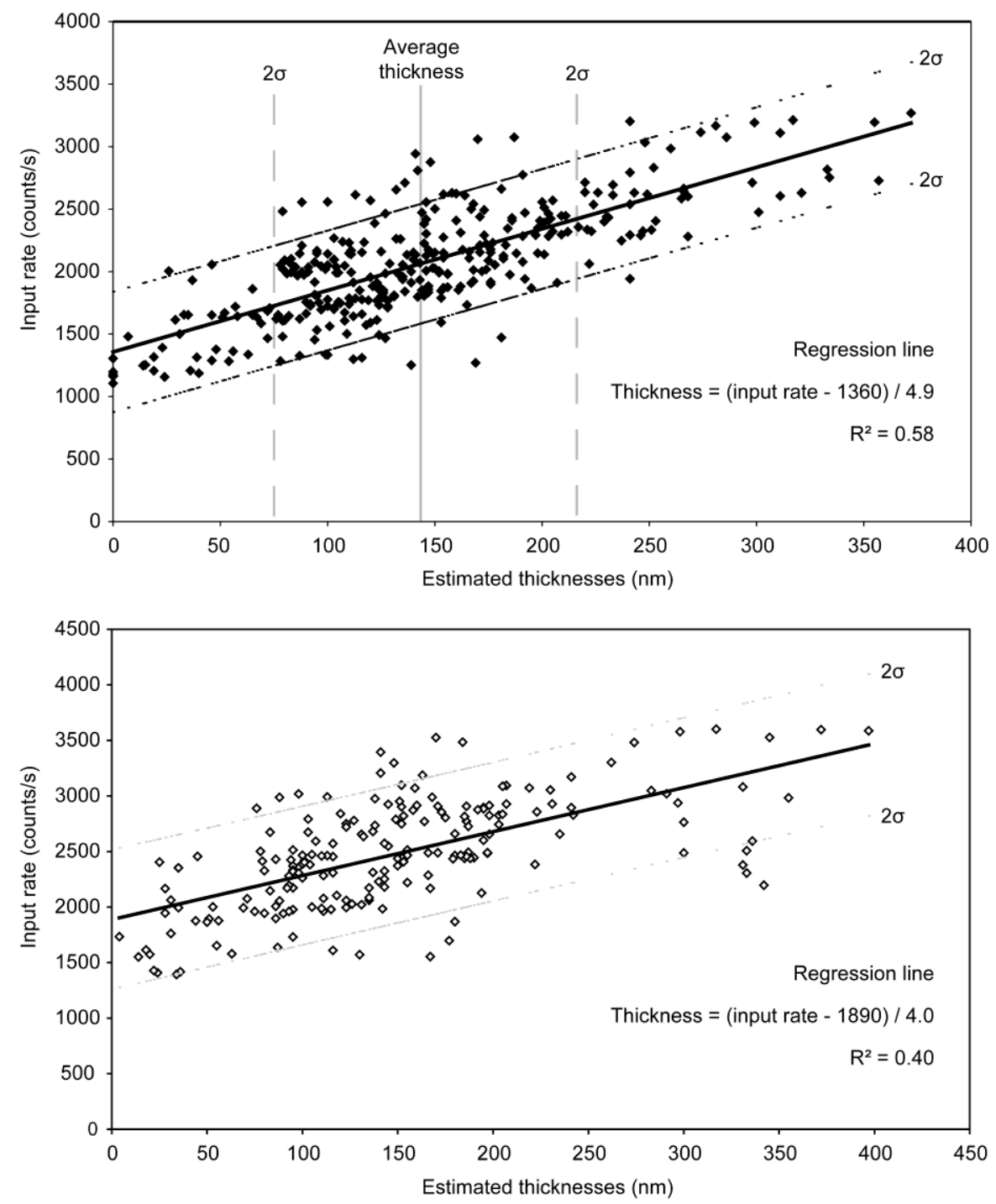

Figure 7. Correlation between the estimated thicknesses and the input rate (in counts/s). a) Case of micas, on 325 analyses on different FIB blades (GL07); b) Case of 197 chlorites analyses (GL07), for which the thickness was estimated from adjacent Fe-poor micas analyses, localized at less than $100 \mathrm{~nm}$ (noted M-chlorite). Absolute input rate values are only valid for the TEM JEOL-2100 F.

\begin{tabular}{|c|c|c|c|c|c|c|}
\hline \multirow{2}{*}{$\begin{array}{l}\text { Sample } \\
\text { Iron valency }\end{array}$} & \multicolumn{3}{|c|}{ Fe-poor sample / TI08 PIII - sp44 } & \multicolumn{3}{|c|}{ Fe-rich sample / GL07 16 A4 - sp15 } \\
\hline & $\begin{array}{c}\text { all } \mathrm{Fe} \text { is } \\
\mathrm{Fe}^{2+}\end{array}$ & $\begin{array}{c}\text { all } \mathrm{Fe} \text { is } \\
\mathrm{Fe}^{3+}\end{array}$ & difference & $\begin{array}{c}\text { all } \mathrm{Fe} \text { is } \\
\mathrm{Fe}^{2+}\end{array}$ & $\begin{array}{c}\text { all } \mathrm{Fe} \text { is } \\
\mathrm{Fe}^{3+}\end{array}$ & difference \\
\hline $\mathrm{Mg}$ & 0.37 & 0.37 & 0.00 & 0.32 & 0.31 & -0.01 \\
\hline $\mathrm{Al}$ & 2.12 & 2.10 & -0.02 & 2.38 & 2.33 & -0.05 \\
\hline $\mathrm{Si}$ & 3.33 & 3.30 & -0.03 & 3.21 & 3.14 & -0.07 \\
\hline K & 1.07 & 1.05 & -0.02 & 0.24 & 0.23 & -0.01 \\
\hline $\mathrm{Fe}$ & 0.22 & 0.22 & 0.00 & 0.51 & 0.49 & 0.02 \\
\hline Total & 7.11 & 7.04 & -0.07 & 6.73 & 6.57 & -0.16 \\
\hline Estimated thickness (nm) & 88 & 95 & +7 & 109 & 133 & +24 \\
\hline
\end{tabular}

Table 2. Influence of the $\mathrm{Fe}^{3+} / \mathrm{Fe}^{2+}$ ratio on the number of cations and indirectly on the thickness estimation. Example of two micas (GL07 and TI08). Results are expressed in apfu for 11 oxygens. 

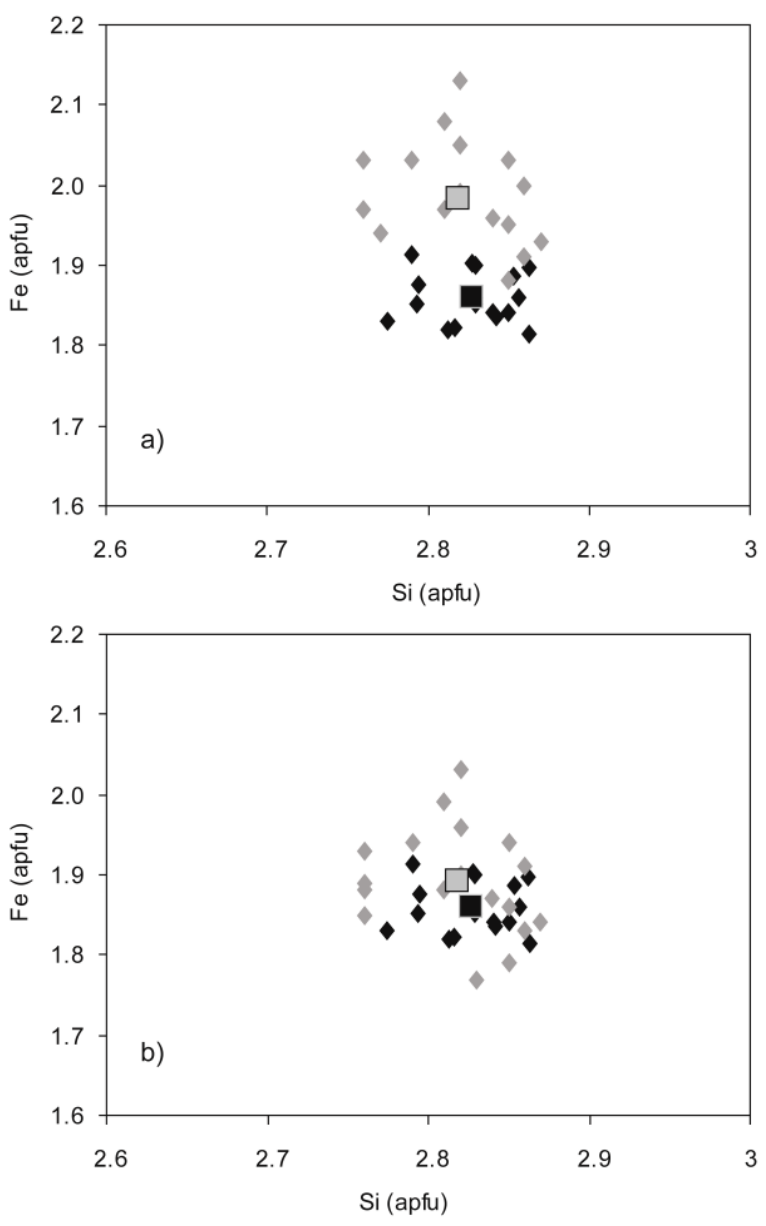

EMPA analysis

EDX-TEM analysis

Average of EMPA analysis

Average of EDX-TEM analyses

Figure 8. Comparison between EMP and $t$ - $O$-protocol EDXTEM results in case of chlorite, for which the thickness was estimated from adjacent Fe-poor micas analyses (noted $\mathrm{M}$ chlorite). Sample TI08 PIII. Estimated thicknesses between 50 and $90 \mathrm{~nm}$. a) Fe vs Si (apfu) contents without corrections. Average of TEM analysis: Si 2.817, Fe 1.98; average of EMP analysis (apfu): Si 2.83, Fe 1.86. b) Fe vs Si (apfu) contents with $t$ - $O$-protocol corrections. Average of TEM analysis: $\mathrm{Si} 2.818, \mathrm{Fe}$ 1.89 vs average of EMP analysis (apfu): Si 2.83, Fe 1.86 .

\subsection{Extension of the $\mathrm{t}$-O-protocol to $\mathrm{Fe}$-rich clay minerals}

As detailed in the former section, the closest Fe-poor micas can be used to estimate the thickness of adjacent chlorites. This approach may be generalized to entire FIB thin sections, as illustrated on Figure 10, where the bright-field TEM image of a FIB thin-section is used as a background. On Figure 10-c, the "topographic" map obtained from the estimated thicknesses of mica is superimposed. Owing to the density of analysis points, it is possible to delimit curves of iso-thickness in chlorite from analysis points of mica, with an assumed precision of $\pm 20 \mathrm{~nm}$ (equal to the difference between two curves of equivalent thicknesses). If it is assumed that the contrast variation is similar for mica and chlorite, Figure 10 shows a very good correlation between the calculated thickness and the image contrast, lightest contrasts underlining thinner parts of the FIB-section (the correlation between contrast and FIB section thickness was checked with SEM). This application may allow for correcting the chemical maps for example (e.g. Vidal et al., 2006).
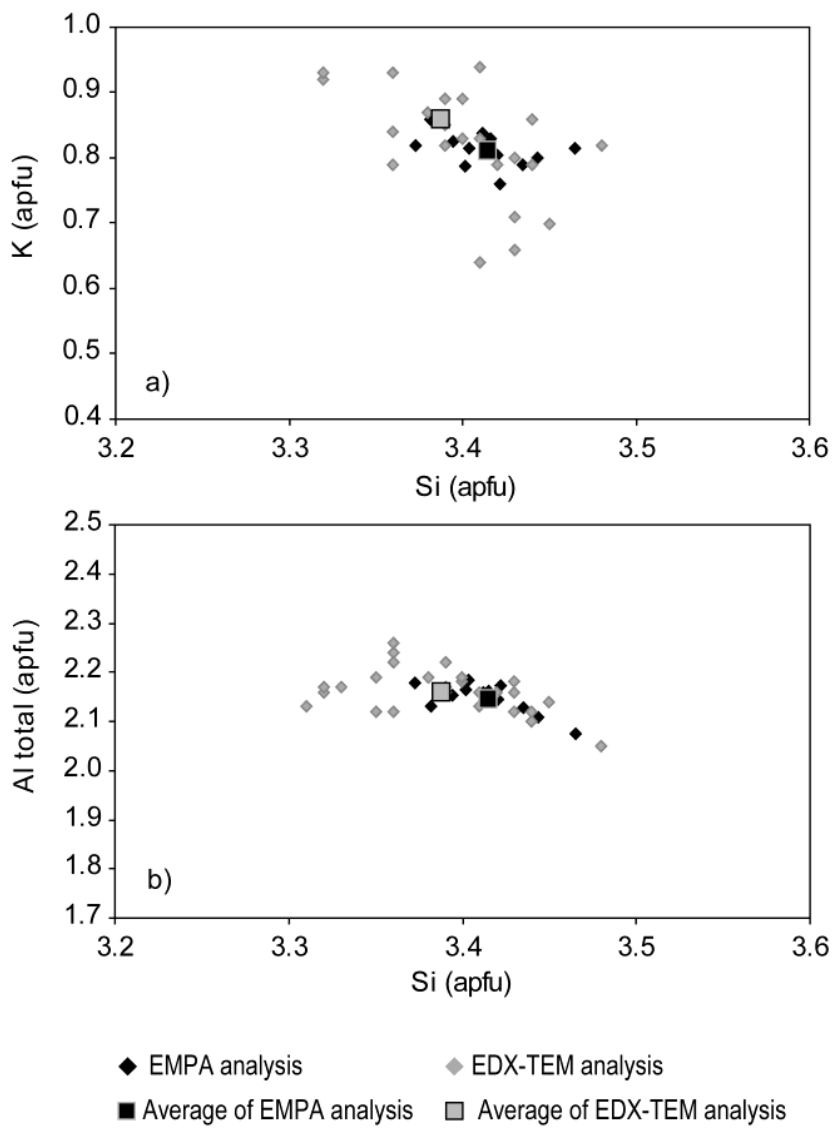

Figure 9. Comparison between EMP and $t$ - $O$-protocol EDXTEM results in case of mica. Sample TI08 PIII. a) K vs $\mathrm{Si}$ (apfu), and b) Al vs Si (apfu). Estimated thicknesses between 30 and $100 \mathrm{~nm}$.

\section{Conclusion}

The FIB milling method is becoming a more and more effective tool in its applications to Earth sciences (e.g. Wirth, 2004). We show here that, with due attention paid, some of its inherent artefacts can be circumvented for its application to clay minerals samples. The main precautions concern both (i) the FIB sectioning and (ii) the analytical procedures and are:

(i-1) decreasing the accelerating voltage and beam intensity during milling in order to avoid amorphization, gallium implantation and material redeposition;

(i-2) avoiding too thin FIB sections (in order to keep a high crystalline/amorphized material ratio);

(ii-1) analyse the crystal close to the Pt strap for metal redeposition;

(ii-2) calibration of the EDX-probe with powders of reference phyllosilicates, in the $(00 l)$ plane;

(ii-3) care for identical analytical conditions during sample and reference-material analysis, including crystalline orientation;

(ii-4) sample thickness evaluation in each analysis point, in order to implement fluorescence and absorption corrections. 


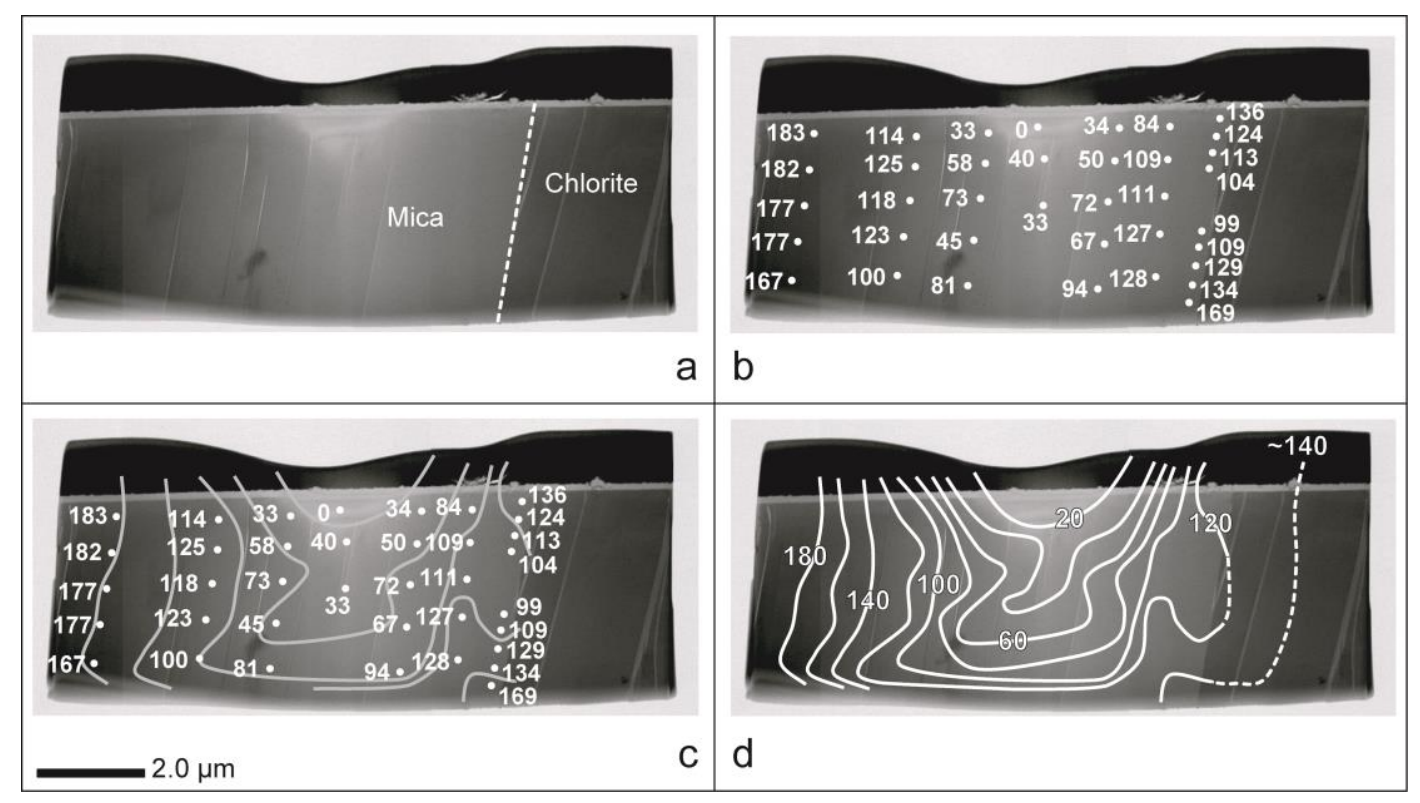

Figure 10. Example of use of the estimated thicknesses on micas to delimit variation of thickness over the entire FIB foil. a) FIB thin section with a mica and a chlorite. Black contrasts underline thicker areas of the FIB blade. b) Mica analyses, and estimation of thicknesses with the $t$ - $O$-protocol. c) Interpolation of level of equivalent thicknesses (in $\mathrm{nm}$ ). d) Extrapolation to the entire FIB blade in the chlorite area.

The protocol developed here for TEM analysis of a non-infinitely thin section with EDX standardization on particles yields results that are in excellent agreement with those of EMP. The $t$ - $O$-protocol is extendable to the whole family of phyllosilicates, in particular to smectites, which have the same structure as micas. In the case of Fe-rich phyllosilicates a limitation is the $\mathrm{Fe}^{3+}$ content, which should be known to evaluate properly the sample thickness. However, the protocol remains applicable for all the phyllosilicates which are $\mathrm{Fe}^{3+}$-poor and therefore offers a viable substitute to EMP for the analysis of submicrometric minerals.

The immense benefit of coupling TEM-EDX with FIB milling is that analyses are performed on areas that could be preselected on the basis of textural or petrological criteria and be extracted with sub-micrometric precision. This opens therefore the field of nanoscale analysis to clay minerals in selected and preserved textures, allowing a true petrological approach down to nanometer scale. Intracrystalline compositional variations or zonations become accessible at this scale and so do local equilibrium that may have controlled mineral chemistry. Potential applications of this technique range from recalibration of phyllosilicate-based thermometers under diagenetic conditions to the fine-scale monitoring of dissolutionrecrystallisation processes in reservoir rocks.

\section{Acknowledgements}

We are most grateful to the materials characterization department of IFP Energies Nouvelles-Lyon, in particular to L. Sorbier, and to the laboratory of CP2M-Université Aix-Marseille, for technical advice. This study was financially supported by IFP Energies Nouvelles, CNRS and ENS Paris. The Glarus samples were collected in the frame of a Partenariat Hubert Curien Germaine De Staël between ENS Paris and Université de Neuchâtel (Suisse).

\section{References}

Battaglia, S., 2004. Variations in the chemical composition of illite from five geothermal fields: a possible geothermometer. Clay Minerals 39, 501-510.

Benzerara, K., Menguy, N., Guyot, F., Vanni, C. Gillet, P., 2005. TEM study of a silicate-carbonate-microbe interface prepared by focused ion beam milling. Geochimica et Cosmochimica Acta $69,1413-1422$.

Bullock, J.F., Humphreys, C.J., Mace, A.J.W., Bishop, H.E. Titchmarsh, J.M., 1985. Crystalline effects in the analysis of semiconductor materials using Auger electrons and X-rays, in: Gullis, A.G. Holt, D.B., (Eds), Crystalline effects in the analysis of semiconductor materials using Auger electrons and X-rays. Adam Hilger, Bristol, pp. 405-410.

Cathelineau, M., 1988. Cation site occupency in chlorites and illites as a function of temperature. Clay Minerals 23, 471-485.

Cathelineau, M. Nieva, D., 1985. A chlorite solid solution geothermometer. The Los Azufres (Mexico) geothermal system. Contributions to Mineralogy and Petrology 91, 235-244.

Cliff, G. Lorimer, G.W., Year. of Conference, 5th European Congress on Electron Microscopy, Manchester, Institute of Physics.

Cliff, G. Lorimer, G.W., 1975. The quantitative analysis of thin specimens. Journal of Microscopy 103, 203-207.

Dubacq, B., Vidal, O. De Andrade, V., 2010. Dehydration of dioctahedral aluminous phyllosilicates: thermodynamic modelling and implications for thermobarometric estimates. Contributions to Mineralogy and Petrology 159, 159-174. 
Giannuzzi, L.A., Prenitzer, B.I. Kempshall, B.W., 2005. Ion Solid interactions, in: Giannuzzi, L.A., (Eds), Ion - Solid interactions. North Carolina State University, Hardcover, 18, pp. 358.

Goldstein, J., Williams, D.B. Cliff, G., 1986. Quantitative Y-ray analysis, in: Joy, D.C., Romig, A.D. Goldstein, J., (Eds), Quantitative Y-ray analysis. Springer, New York, pp. 448.

Hamilton, D.L. Henderson, C.M.B., 1968. The preparation of silicate compositions by gelling method. Mineralogical Magazine 36, 832-838.

Heaney, P.J., Vicenzi, E.P., Giannuzzi, L.A. Livi, K.J.T., 2001. Focused ion beam milling: A method of site-specific sample extraction for microanalysis of Earth and planetary materials. American Mineralogist 86, 1094-1099.

Hillier, S. Velde, B., 1991. Octahedral Occupancy and the Chemical-Composition of Diagenetic (Low-Temperature) Chlorites. Clay Minerals 26, 149-168.

Jacobs, M.H. Barborovska, J., Year. of Conference, 5th European Congress on Electron Microscopy, Manchester, Institute of Physics.

Jahren, J.S. Aagaard, P., 1992. Diagenetic Illite-Chlorite Assemblages in Arenites .1. Chemical Evolution. Clays and Clay Minerals 40, 540-546.

Kim, S.T. Dravid, V.P., 2000. Focused ion beam sample preparation of continuous fibre-reinforced ceramic composite specimens for transmission electron microscopy. Journal of Microscopy-Oxford 198, 124-133.

Lahfid, A., Beyssac, O., Deville, E., Negro, F., Chopin, C. Goffe, B., 2010. Evolution of the Raman spectrum of carbonaceous material in low-grade metasediments of the Glarus Alps (Switzerland). Terra Nova 22, 354-360.

Obst, M., Gasser, P., Mavrocordatos, D. Dittrich, M., 2005. TEM-specimen preparation of cell/mineral interfaces by Focused Ion Beam milling. American Mineralogist 90, 1270-1277.

Parra, T., Vidal, O. Agard, P., 2002. A thermodynamic model for $\mathrm{Fe}-\mathrm{Mg}$ dioctahedral $\mathrm{K}$ white micas using data from phaseequilibrium experiments and natural pelitic assemblages. Contributions to Mineralogy and Petrology 143, 706-732.

Parra, T., Vidal, O. Jolivet, L., 2002. Relation between the intensity of deformation and retrogression in blueschist metapelites of Tinos Island (Greece) evidenced by chlorite-mica local equilibria. Lithos 63, 41-66.

Parra, T., Vidal, O. Theye, T., 2005. Experimental data on the Tschermak substitution in Fe-chlorite. American Mineralogist 90, 359-370.
Salvat, F., Fernandez-Varea, J.M. Sempau, J. (2006). PENELOPE-2006: A code system for Monte-Carlo simulation of electron and photon transport. Barcelona, Spain, Nuclear Energy Agency.

Van Cappellen, E. Doukhan, J.C., 1994. Quantitative Transmission-X-Ray Microanalysis of Ionic Compounds. Ultramicroscopy 53, 343-349.

Vidal, O., De Andrade, V., Lewin, E., Munoz, M., Parra, T. Pascarelli, S., 2006. P-T-deformation-Fe3+/Fe2+ mapping at the thin section scale and comparison with XANES mapping: application to a garnet-bearing metapelite from the Sambagawa metamorphic belt (Japan). Journal of Metamorphic Geology 24, 669-683

Vidal, O. Parra, T., 2000. Exhumation paths of high-pressure metapelites obtained from local equilibria for chlorite-phengite assemblages. Geological Journal 35, 139-161.

Vidal, O., Parra, T. Trotet, F., 2001. A thermodynamic model for $\mathrm{Fe}-\mathrm{Mg}$ aluminous chlorite using data from phase equilibrium experiments and natural pelitic assemblages in the 100 degrees to 600 degrees C, 1 to $25 \mathrm{~kb}$ range. American Journal of Science 301, 557-592.

Watanabe, M., Horita, Z. Nemoto, M., 1996. Absorption correction and thickness determination using the zeta factor in quantitative X-ray microanalysis. Ultramicroscopy 65, 187-198.

Watanabe, M. Williams, D.B., 1999. The new form of the $\zeta$ factor method for quantitative microanalysis in AEM-XEDS and its evaluation, in: Bailey, S.W., Jerome, W.G., McKernan, S., Mansfield, J.F. Price, R.L., (Eds), The new form of the $\zeta$-factor method for quantitative microanalysis in AEM-XEDS and its evaluation. Springer, New York, 5, pp. 88-89.

Watanabe, M. Williams, D.B., 2006. The quantitative analysis of thin specimens: a review of progress from the Cliff-Lorimer to the new zeta-factor methods. Journal of Microscopy-Oxford 221, 89-109.

Wirth, R., 2004. Focused Ion Beam (FIB): A novel technology for advanced application of micro- and nanoanalysis in geosciences and applied mineralogy. European Journal of Mineralogy 16, 863-876.

Ziegler, J.F., 1998. The stopping and range of ions in matter (SRIM-2000), IBMresearch, Yorktown, N.Y.

Ziegler, J.F., Biersack, J.P. Littmark, U., 1985. The stopping and range of ions in solids, Pergamon Press, New York.

Ziegler, J.F., Ziegler, M.D. Biersack, J.P., 2010. The stopping and range of ions in matter (SRIM - 2008.04), from http://www.srim.org/SRIM/SRIM2008.htm. 